\title{
(6) OPEN ACCESS \\ Do short birth intervals have long-term implications for parental health? Results from analyses of complete cohort Norwegian register data
}

\author{
Emily Grundy, Øystein Kravdal ${ }^{2}$
}

\begin{abstract}
- Additional material is published online only. To view please visit the journal online (http://dx.doi.org/10.1136/jech2014-204191)

${ }^{1}$ Department of Social Policy, London School of Economics, London, UK

${ }^{2}$ Department of Economics, University of Oslo, Oslo, Norway
\end{abstract}

Correspondence to Professor Emily Grundy, Department of Social Policy, London School of Economics, Houghton Street,

London WC2A 2AE, UK. e.m.grundy@lse.ac.uk

Received 24 March 2014 Revised 29 May 2014 Accepted 21 June 2014 Published Online First 9 July 2014

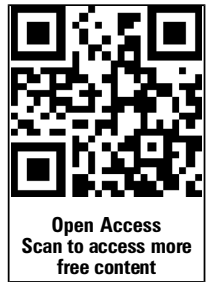

\begin{abstract}
Background Short and very long interbirth intervals are associated with worse perinatal, infant and immediate maternal outcomes. Accumulated physiological, mental, social and economic stresses arising from raising children close in age may also mean that interbirth intervals have longer term implications for the health of mothers and fathers, but few previous studies have investigated this.

Methods Discrete-time hazards models were estimated
\end{abstract} to analyse associations between interbirth intervals and mortality risks for the period 1980-2008 in complete cohorts of Norwegian men and women born during 1935-1968 who had had two to four children.

Associations between interbirth intervals and use of medication during 2004-2008 were also analysed using ordinary least-squares regression. Covariates included age, year, education, age at first birth, parity and change in coparent since the previous birth.

Results Mothers and fathers of two to three children with intervals between singleton births of less than 18 months, and mothers of twins, had raised mortality risks in midlife and early old age relative to parents with interbirth intervals of 30-41 months. For parents with three or four children, longer average interbirth intervals were associated with lower mortality. Short intervals between first and second births were also positively associated with medication use. Very long intervals were not associated with raised mortality or medication use when change of coparent since the previous birth was controlled.

Conclusions Closely spaced and multiple births may have adverse long-term implications for parental health. Delayed entry to parenthood and increased use of fertility treatments mean that both are increasing, making this a public health issue which needs further investigation.

\section{INTRODUCTION}

In poorer and richer countries, adverse birth outcomes are associated with short and very long birth intervals, ${ }^{1-8}$ and the WHO recommends an interval of at least 24 months from a live birth to the next pregnancy. ${ }^{9}$ Interpregnancy or interbirth intervals have additionally been associated with short-term maternal outcomes, again with some indication of a U-shaped association. ${ }^{10-12}$ The causal mechanisms underlying these associations are hypothesised to include pathways through maternal nutrition, particularly folate status. ${ }^{12-15}$ Lack of sufficient time to return to the normal prepregnancy metabolic state before the next pregnancy may also initiate processes with longer term implications; for example, a prospective US study found that risks of maternal obesity increased with each interpregnancy interval of $<12$ months. ${ }^{16}$ The physical, emotional and economic strains involved in meeting the needs of two or more children close in age may also lead to stresses relevant to health. Mothers of twins, for example, suffer from higher rates of postnatal depression than mothers of singletons ${ }^{17-19}$ and multiple births are associated with higher risks of subsequent divorce. $^{20}$ Similar, if less marked, effects might apply to parents of closely spaced singleton children. Very long gaps between births may result in maternal physiological regression such that risks for mothers (and infants) revert to those associated with primiparous women. ${ }^{6}$ Unusually, widely spaced families may also result in social stress. Apart from these hypothesised linkages, selection effects may be relevant. Closely spaced childbearing may reflect less breast feeding and less efficient use of contraception and be associated with other health behaviours and socioeconomic status. Very long intervals may be a consequence of poor parental health status, impaired fecundity or partnership breakdown, ${ }^{21-24}$ all of which have implications for later health.

Given the importance of accumulated life course effects on health in later life, ${ }^{25}$ stresses associated with short interbirth intervals may have longer term health implications for mothers and fathers. In this study, we investigate this using Norwegian Population Register data for complete cohorts born during 1935-1968.

To the best of our knowledge, only two previous studies have investigated this, both of which used a dichotomised indicator of whether parents had experienced any interbirth interval of less than 18 months and relied on some retrospective reporting of fertility histories. The first used linked census and vital registration data for 1\% of the population of England and Wales and found that among women born during 1911-1920, mothers of twins and those with any interbirth interval of less than 18 months had raised mortality risks at ages 50-89. In later born cohorts, mortality was raised among mothers of twins, but not among mothers of closely spaced singletons. ${ }^{26}$ A later British study based on panel data for parents aged 50-83 found that experience of any interbirth interval of less than 18 months (including twins) was positively associated with poor self-rated health among women and with health limitations among women and men. ${ }^{27}$

In this study, we employ a detailed categorisation of interbirth intervals rather than a dichotomous 
indicator in order to see whether longer term effects of birth interval lengths follow a U-shaped association similar to that reported for short-term maternal outcomes. We hypothesised that stresses associated with short interbirth intervals might be cumulative and investigate effects of experience of more than one short interval and average interval length, as well as examining parity-specific effects. We consider women and men as this may clarify the extent to which any associations reflect longterm physiological consequences for women or broader biosocial effects relevant to mothers and fathers.

\section{METHODS}

\section{Data and measures}

The Norwegian Central Population Register includes everyone who has ever lived in Norway since 1960, all of whom are assigned a personal identification number. Identification numbers of parents have been recorded at registration of births since 1964, and for those born earlier, parents were identified for children living in the parental household at the 1970 census (usual among those then younger than 18). Thus, parents are identified for almost all children born after 1953, and conversely, almost complete maternity and paternity histories can be assembled for women and men born after $1935 .^{28}$ Other registers using the same identification number include an Educational Database and, since 2004, the Norwegian Prescription Database. ${ }^{29}$ This records all purchases of prescription medication (defined by Anatomical Therapeutic Code (ATC)) by all residents except those in healthcare institutions.

We analyse mortality at age 40 and over, when women have very largely completed their childbearing, for the period 19802008 and purchase of prescription medicine during the period 2004-2008. As the exposure of interest is birth interval length, those with only one child are excluded. To simplify the analysis, we also excluded the $5 \%$ of parents who had had five or more children.

\section{Interbirth intervals}

Birth interval length was grouped into seven categories denoting at one end of the distribution multiple births and at the other intervals of 90 or more months. The interval 30-41 months, which includes the WHO recommended minimum interval, was used as the reference category. For data protection reasons, only year of births was available for the analysis of medication purchase. For this analysis, we therefore categorised birth interval lengths in years, ranging from less than 1 (including multiple births) to seven or more.

\section{Covariates}

Our outcome variables include deaths observed during a 28-year period when mortality rates fell substantially and fertility changed. We therefore control for period of observation in the mortality models and age in all analyses. Fertility patterns are strongly associated with level of education and marital status, both of which are also associated with health, ${ }^{23} 28$ we therefore also included these in all models. In a separate step, we added controls for age at first birth and total number of children born. Both are associated with later-life mortality ${ }^{26} 273031$ and are likely to be associated with birth interval lengths (eg, women who start childbearing at older ages may compress subsequent birth intervals ${ }^{5}{ }^{21}$ ). Very long birth intervals may be associated with repartnering after partnership disruption, which is associated with later health and mortality. ${ }^{23} 24$ In a final step, we therefore included an indicator of whether there had been a change of coparent over the birth interval.

\section{STATISTICAL ANALYSIS}

\section{Mortality analysis}

Discrete-time hazard models were estimated following standard procedures. $^{32}$ A series of 1-year observations was created, starting in January of the year the person turned 40 or, for those born during 1935-1939, from the beginning of 1980. The last observation was the year of death, the year of emigration or 2008, whichever came first. Owing to the fact that everyone included in the analysis was born in 1935 or later and the last possible year of observation is 2008, the oldest age considered is 73 . In the period considered, fewer than $2 \%$ of men and $1 \%$ of women died before age 40, so those included constitute the vast majority of their respective birth cohorts. ${ }^{33}$

After excluding observations relating to absences abroad, sexspecific logistic models were estimated using the Proc Logistic procedure in the SAS software suite. All variables refer to the situation at the beginning of each 1-year observation period or are by definition constant.

\section{Analysis of prescription drug purchase}

Approaches to deriving morbidity indicators from medication data vary considerably. ${ }^{34-37}$ We used the total number of different medicines purchased (defined as the first five ATC digits being different) and the total number of diseases inferred using Kuo et al's ${ }^{38}$ identification of 32 conditions treated by drugs uniquely prescribed for these conditions.

We estimated ordinary least-squares models for the total number of different drug purchases during 2004-2008, and for the number of different diseases inferred from these purchases, for women and men aged 40-69 years in 2004 and alive and in the country throughout 2004-2008.

\section{RESULTS}

\section{Descriptive results}

Table 1 shows the number of deaths and distribution of exposure time by variables used in the analysis; table 2 presents the distribution by sociodemographic characteristics and length of the first interbirth interval. Fifty-three per cent of the study population had two births, 35\% three and $12 \%$ four. One per cent of parents had had a twin birth first; a further $10 \%$ had a first interbirth interval shorter than 18 months and $18 \%$ had intervals longer than 5 years. Intervals of less than 18 months between first and second singleton births were inversely related to the level of education and showed a U-shaped association with age at first birth. The association between birth interval lengths and overall parity is evident in the higher proportion of high parity parents with a short first interbirth interval. The well-established increase in twinning rates with maternal age is evident in the linear increase in twin first maternities with older age at first birth. There was a strong association between very long intervals and a change of coparent across the interval. Distributions for subsequent birth intervals (see online supplementary table S1) showed slightly higher proportions of multiple births, lower proportions of intervals of $0>18$ months and higher proportions with very long intervals.

\section{Model results}

Table 3 shows estimates from the three previously described models of variation in mortality associated with the length of the first, second and third interbirth intervals. Relative to those with interbirth intervals of 30-41 months, results from model 3 show that first intervals between singleton births of less than 18 months were associated with higher mortality risks of $12-$ 
Table 1 Number of deaths and distribution (\%) of exposure time, men and women born during 1935-1968 and aged 40-73 years in 1980-2008 who had had two to four children

\begin{tabular}{|c|c|c|c|c|}
\hline & \multicolumn{2}{|l|}{ Men } & \multicolumn{2}{|l|}{ Women } \\
\hline & Deaths & $\begin{array}{l}\text { Per cent of } \\
\text { exposure time }\end{array}$ & Deaths & $\begin{array}{l}\text { Per cent of } \\
\text { exposure time }\end{array}$ \\
\hline \multicolumn{5}{|l|}{ Period } \\
\hline 1980-1984 & 1378 & 5.7 & 757 & 5.5 \\
\hline 1985-1989 & 3180 & 10.6 & 1871 & 10.4 \\
\hline 1990-1994 & 5151 & 15.5 & 3207 & 15.3 \\
\hline 1995-1999 & 8212 & 20.2 & 5363 & 20.2 \\
\hline 2000-2004 & 12018 & 24.8 & 8321 & 25.0 \\
\hline $2005-2008$ & 13348 & 23.2 & 9213 & 23.6 \\
\hline \multicolumn{5}{|l|}{ Age group } \\
\hline 40-44 & 4006 & 27.5 & 2717 & 28.0 \\
\hline $45-49$ & 6186 & 24.8 & 4084 & 24.5 \\
\hline $50-54$ & 7564 & 19.5 & 5060 & 19.2 \\
\hline $55-59$ & 8498 & 14.2 & 5802 & 14.1 \\
\hline $60-64$ & 8583 & 8.9 & 5529 & 8.9 \\
\hline $65-69$ & 6310 & 4.2 & 4087 & 4.3 \\
\hline $70-73$ & 2140 & 1.0 & 1453 & 1.1 \\
\hline \multicolumn{5}{|l|}{ Education (years) } \\
\hline 10 & 15227 & 23.7 & 12483 & 29.5 \\
\hline $11-13$ & 20083 & 46.8 & 12256 & 46.9 \\
\hline $14-17$ & 5838 & 20.3 & 3617 & 21.0 \\
\hline $18+$ & 2139 & 9.2 & 376 & 2.6 \\
\hline \multicolumn{5}{|l|}{ Marital status } \\
\hline Never-married & 882 & 2.6 & 447 & 2.6 \\
\hline Married & 29304 & 81.4 & 18587 & 76.5 \\
\hline Widowed & 1383 & 1.2 & 3036 & 4.5 \\
\hline Separated/divorced & 11718 & 14.8 & 6662 & 16.4 \\
\hline \multicolumn{5}{|l|}{ Number of children } \\
\hline 2 & 22112 & 53.9 & 14736 & 53.1 \\
\hline 3 & 15093 & 34.7 & 10015 & 35.1 \\
\hline 4 & 6082 & 11.4 & 3981 & 11.8 \\
\hline \multicolumn{5}{|l|}{ Age at first birth } \\
\hline$<20$ & 1485 & 2.5 & 5187 & 13.6 \\
\hline $20-22$ & 9035 & 16.5 & 9932 & 30.8 \\
\hline $23-25$ & 13225 & 28.3 & 7205 & 26.8 \\
\hline $26-28$ & 9910 & 25.0 & 3838 & 16.4 \\
\hline $29-31$ & 5381 & 14.9 & 1616 & 7.6 \\
\hline $32-34$ & 2455 & 7.4 & 661 & 3.1 \\
\hline $35-37$ & 1027 & 3.4 & 222 & 1.2 \\
\hline $38+$ & 769 & 2.1 & 71 & 0.4 \\
\hline \multicolumn{5}{|c|}{ Change of coparent birth 1-2 } \\
\hline No & 40132 & 93.8 & 26160 & 93.0 \\
\hline Yes & 3155 & 6.2 & 2572 & 7.0 \\
\hline \multicolumn{5}{|c|}{ Change of coparent birth 2-3 } \\
\hline No & 19234 & 42.5 & 12918 & 44.0 \\
\hline Yes & 1941 & 3.6 & 1978 & 2.9 \\
\hline Not applicable & 22112 & 53.9 & 14736 & 53.1 \\
\hline \multicolumn{5}{|c|}{ Change of coparent birth 3-4 } \\
\hline No & 5486 & 10.5 & 3685 & 11.1 \\
\hline Yes & 596 & 0.9 & 296 & 0.8 \\
\hline Not applicable & 37205 & 88.6 & 24751 & 88.2 \\
\hline $\begin{array}{l}\text { Total deaths/person years } \\
\text { of exposure (000s) }\end{array}$ & 43287 & 10601.7 & 28732 & 11060.0 \\
\hline
\end{tabular}

$13 \%$ among women and $16-17 \%$ among men. Twin first maternities were associated with an excess mortality risk of $15 \%$ but mortality among fathers of twins was not raised. Associations between mortality risks and short second birth intervals were similar, although smaller. Among the small proportion of parents with four births, mortality was raised for those with third interbirth intervals of 18-29 months, but not for those with intervals shorter than this. Results from models 2 and 1 were close to those from the fully adjusted model, except that the association between a twin birth and female mortality was slightly stronger in models including the other fertility variables. There was more variation between different models in results for associations between very long intervals and mortality risks. In model 1 and, to a lesser extent, model 2, a first interbirth interval of $60-89$ or $90+$ months was positively associated with mortality but a high proportion of these parents $(47 \%$ of men and $43 \%$ of women) had experienced a change of coparent; when this variable was included (model 3), the direction of the association changed. Associations between very long second interbirth intervals and mortality were similar; very long third intervals were associated with lower mortality among men in the fully adjusted model, but not significantly so for women.

Associations between other covariates and mortality risks are presented for the first interbirth interval in online supplementary table S2. Mortality risks increased with age and decreased with the period of observation and years of education. They were raised for non-married groups, particularly the divorced, and reduced with older age at first birth and higher parity. As already implied, they were raised among those who had their second child with a different coparent from the first (OR for women 1.33 (1.27-1.39); for men 1.24 (1.19-1.29)).

\section{Cumulative and parity-specific effects}

Table 4 presents parity-specific analyses of associations between mortality and short birth intervals, number of short birth intervals and average interval length. Models include all covariates previously described (model 3), other than parity. Intervals of less than 18 months between the first and second births were associated with raised mortality risks for women and men of all parities; short intervals between the second and third births were associated with raised mortality for women with three children and for men with three or four children. There was no association between a short third birth interval and mortality of the relatively small group with four children. Mortality risks were raised for women who had a twin birth first or second and no later children but not for women who had another birth after twins. Intervals of 90 or more months between successive births (not shown) were negatively associated with mortality for relevant parity groups, except in the case of the interval between the third and fourth births where the estimate of 0.90 for women was not statistically significant.

Fathers who had had three closely spaced children had higher mortality than fathers of two closely spaced children. However, for women with three children, and mothers and fathers of four children, effects tended to increase with the number of short birth intervals but differences were relatively small and not statistically significant. There was an inverse association between mortality and average birth interval length. We also undertook analyses (not shown), additionally controlling for lengths of interbirth intervals other than the one under consideration. Results were only trivially different from those presented here as correlations between birth interval lengths were weak.

\section{Prescribed medication use}

Table 5 shows results of analyses of associations between the first interbirth interval length and number of different prescription drug purchases and number of inferred diseases. Results 
Table 2 Distribution by length of first interbirth interval, education, marital status, age at first birth, parity and change of coparent since previous birth

\begin{tabular}{|c|c|c|c|c|c|c|c|c|c|c|c|c|c|c|c|c|c|c|}
\hline & \multicolumn{18}{|c|}{ Length of 1st interbirth interval (months) } \\
\hline & \multicolumn{9}{|c|}{ Men } & \multicolumn{9}{|c|}{ Women } \\
\hline & 0 & $1-17$ & $18-29$ & $30-41$ & $42-59$ & $60-89$ & $90+$ & Deaths & $\begin{array}{l}\text { Person- } \\
\text { years } \\
(000 s)\end{array}$ & 0 & $1-17$ & $18-29$ & $30-41$ & $42-59$ & $60-89$ & $90+$ & Deaths & $\begin{array}{l}\text { Person- } \\
\text { years } \\
(000 s)\end{array}$ \\
\hline \multicolumn{19}{|l|}{ Education } \\
\hline 10 years & 1.0 & 13.4 & 25.6 & 21.9 & 18.8 & 11.7 & 7.8 & 15227 & 2498.8 & 0.8 & 12.3 & 25.8 & 21.9 & 19.5 & 12.3 & 7.4 & 12483 & 3259.3 \\
\hline $11-13$ & 1.0 & 10.0 & 25.4 & 24.7 & 20.9 & 11.4 & 6.5 & 20083 & 4965.9 & 0.9 & 10.4 & 25.3 & 24.6 & 21 & 11.6 & 6.2 & 12256 & 5191.7 \\
\hline $14-17$ & 1.2 & 7.3 & 25.5 & 26.4 & 21.8 & 11.5 & 6.5 & 5838 & 2161.2 & 1.2 & 7.8 & 27.6 & 26.5 & 20.6 & 10.6 & 5.8 & 3617 & 2322.7 \\
\hline $18+$ & 1.2 & 6.8 & 29.5 & 27.5 & 20.0 & 9.7 & 5.2 & 2139 & 975.8 & 1.5 & 6.7 & 29.2 & 25.9 & 20 & 10.7 & 6.1 & 376 & 286.3 \\
\hline \multicolumn{19}{|l|}{ Marital status } \\
\hline Never-married & 2.2 & 5.8 & 19.7 & 19.6 & 19.9 & 16.9 & 15.9 & 882 & 359.0 & 2.4 & 4.5 & 17.4 & 18.2 & 19.2 & 18.1 & 20.4 & 447 & 287.5 \\
\hline Married & 1.0 & 9.8 & 26.3 & 25.4 & 20.8 & 11.0 & 5.8 & 29304 & 8543.3 & 0.9 & 10.1 & 26.4 & 25.1 & 20.8 & 11.2 & 5.6 & 18587 & 8458.4 \\
\hline Div/sep & 1.1 & 11.5 & 24.8 & 22.0 & 19.0 & 12.0 & 9.7 & 11718 & 1573.6 & 1.0 & 11.4 & 25.4 & 21.9 & 19.4 & 12.4 & 8.4 & 6662 & 1815.7 \\
\hline Widowed & 0.9 & 13.0 & 26.7 & 22.7 & 19.8 & 11.5 & 5.5 & 1383 & 125.8 & 0.8 & 13.8 & 27.5 & 22.3 & 18.9 & 10.9 & 5.8 & 3036 & 498.5 \\
\hline \multicolumn{19}{|l|}{ Age at 1st birth } \\
\hline$<20$ & 0.5 & 11.7 & 20.3 & 15.5 & 18.9 & 16.0 & 15.9 & 1485 & 260.7 & 0.5 & 13.5 & 24.5 & 19.5 & 18.7 & 13.2 & 10.2 & 5187 & 1505.7 \\
\hline $20-22$ & 0.6 & 12.7 & 24.0 & 20.8 & 19.6 & 12.8 & 9.6 & 9035 & 1746.3 & 0.6 & 12.4 & 25.4 & 22.4 & 19.8 & 11.9 & 7.4 & 9932 & 3408.1 \\
\hline $23-25$ & 0.7 & 11.3 & 25.0 & 23.8 & 20.8 & 11.3 & 7.1 & 13225 & 3002.7 & 0.8 & 9.2 & 25.2 & 25.7 & 21.7 & 11.4 & 5.9 & 7205 & 2968.4 \\
\hline $26-28$ & 0.9 & 8.8 & 25.5 & 26.4 & 21.4 & 11.0 & 5.9 & 9910 & 2649.8 & 1.1 & 7.4 & 26.2 & 27.3 & 21.9 & 11.1 & 5.0 & 3838 & 1816.6 \\
\hline 29-31 & 1.2 & 7.5 & 26.6 & 27.1 & 21.2 & 11.2 & 5.3 & 5381 & 1575.7 & 1.6 & 7.4 & 28.5 & 27.2 & 20.7 & 10.8 & 3.8 & 1616 & 836.9 \\
\hline $32-34$ & 1.7 & 7.5 & 28.8 & 27.0 & 20.4 & 10.6 & 4.0 & 2455 & 785.4 & 2.6 & 7.9 & 33.1 & 26.4 & 18.9 & 9.1 & 2.1 & 661 & 345.3 \\
\hline $35-37$ & 2.8 & 8.2 & 32.5 & 26.9 & 18.3 & 8.4 & 2.9 & 1027 & 363.9 & 5.0 & 9.6 & 36.3 & 26.0 & 16.5 & 5.8 & 0.9 & 222 & 136.4 \\
\hline $38+$ & 5.3 & 10.7 & 35.4 & 25.0 & 14.9 & 6.7 & 2.1 & 769 & 217.3 & 8.7 & 13.9 & 38.4 & 23.6 & 12.0 & 3.2 & 0.2 & 71 & 42.5 \\
\hline \multicolumn{19}{|l|}{ Number of children } \\
\hline 2 & 1.0 & 5.8 & 20.2 & 25.1 & 24.8 & 14.8 & 8.4 & 22112 & 5715.0 & 0.9 & 5.8 & 19.7 & 24.5 & 24.8 & 15.4 & 9.1 & 14736 & 5872.1 \\
\hline 3 & 1.1 & 12.5 & 31.2 & 25.5 & 16.9 & 7.8 & 5.0 & 15093 & 3676.7 & 1.0 & 13 & 31.6 & 25.4 & 17.1 & 8.0 & 3.9 & 10015 & 3879.1 \\
\hline 4 & 1.3 & 21.8 & 36.3 & 19.8 & 11.4 & 5.9 & 3.6 & 6082 & 1210.0 & 1.2 & 22.8 & 37.9 & 19.9 & 11.2 & 4.9 & 2.0 & 3981 & 1308.8 \\
\hline \multicolumn{19}{|c|}{ Change of coparent } \\
\hline No & 1.1 & 10.2 & 27.1 & 25.8 & 21.1 & 10.7 & 3.9 & 40132 & 9946.4 & 1.0 & 10.9 & 27.3 & 25.3 & 20.9 & 10.7 & 4.0 & 26160 & 10288.3 \\
\hline Yes & 0.2 & 6.1 & 5.9 & 6.7 & 11.6 & 20.5 & 49.0 & 3155 & 655.3 & 0.4 & 3.4 & 8.9 & 9.9 & 15.1 & 23.0 & 39.3 & 2572 & 771.7 \\
\hline All & 1.0 & 10.0 & 25.8 & 24.6 & 20.5 & 11.3 & 6.7 & 43287 & 10601.7 & 1.0 & 10.3 & 26.0 & 24.2 & 20.5 & 11.5 & 6.4 & 28732 & 11060.0 \\
\hline
\end{tabular}

from mortality analyses relating to deaths during 2004-2008, including classification of birth intervals in years, are also shown. Results show a positive association between short first interbirth intervals and drug purchase and inferred number of diseases. The excess mortality among those having two children in the same or successive years is of a similar magnitude for men, but rather lower for women, as the previously shown excess mortality among those with a first interval shorter than 18 months. Results did not show the same low mortality for those with long birth intervals as found in the fully adjusted model in the main analysis. Supplementary analyses, not shown, indicate that these differences are more the result of the restriction to 2004-2008 than the use of intervals grouped in years rather than months.

\section{DISCUSSION}

Most previous studies of the implications of birth interval lengths for parental health have focused on short-term implications for mothers. We investigated longer term effects and considered fathers as well as mothers. Results showed that mortality risks at ages 40-73 years were raised for mothers and fathers who had intervals of less than 18 months between singleton births and for mothers of multiple births; that mortality risks decreased with the average length of the birth interval (for parents with more than one interval); for men, there was also some indication of a cumulative effect of experiencing more than one short birth interval. The analysis of purchases of prescription medicine similarly suggested an association between short birth intervals and poorer later health. These results are consistent with two previous UK studies which reported positive associations between short birth intervals and mortality among women, ${ }^{26}$ and later-life health impairment among women and men. ${ }^{27}$ Our results on associations between twin maternities and later mortality are less consistent with previous studies. Tomassini et $a l^{39}$ found no significant raised mortality after age 45 among mothers and fathers of twins in Denmark and raised mortality or more long-term illness in only some cohorts of mothers of twins in England and Wales. However, in the analysis of Danish data, which was undertaken using indirect standardisation, it was not possible to control for socioeconomic status or compare parents of twins with other parents, rather than with the whole population including the childless.

Some previous studies have shown associations between very long interbirth intervals and adverse perinatal and short-term maternal outcomes. ${ }^{6}$ We were unable to identify any previous studies examining the possible long-term consequences of very long birth intervals. Our results showed that very long birth intervals were associated with higher mortality risk in models including control for sociodemographic and fertility variables but that this association disappeared or even reversed when change of coparent since the previous birth was controlled. This suggests that it is the partnership disruption which often 
Table 3 Associations between length of interbirth interval and mortality in 1980-2008 (ORs and 95\% Cls from discrete-time hazards models), men and women born during 1935-1968 and aged 40-73 years with two to four children.

\begin{tabular}{|c|c|c|c|c|c|c|}
\hline \multirow[b]{2}{*}{ Months } & \multicolumn{3}{|l|}{ Men } & \multicolumn{3}{|l|}{ Women } \\
\hline & Model 1 & Model 2 & Model 3 & Model 1 & Model 2 & Model 3 \\
\hline \multicolumn{7}{|c|}{ Interval 1st-2nd birth (parents with $2+$ births) } \\
\hline 0 & 1.01 (0.97 to 1.12$)$ & $1.05(0.94$ to 1.16$)$ & $1.05(0.95$ to 1.16$)$ & $1.11(0.98$ to 1.25$)$ & $1.14 *(1.01$ to 1.29$)$ & $1.15^{*}(1.01$ to 1.30$)$ \\
\hline $0>18$ & $1.18^{* *}(1.14$ to 1.22$)$ & $1.17^{* *}(1.13$ to 1.21$)$ & $1.17^{* *}(1.13$ to 1.21$)$ & $1.10^{* *}(1.06$ to 1.15$)$ & $1.12^{* *}(1.07$ to 1.16$)$ & $1.13^{* *}(1.08$ to 1.17$)$ \\
\hline $18-29$ & $1.04^{* *}(1.02$ to 1.07$)$ & $1.05^{* *}(1.02$ to 1.08$)$ & $1.05^{* *}(1.02$ to 1.08$)$ & 1.01 (0.97 to 1.04 ) & 1.02 (0.98 to 1.05$)$ & $1.02(0.99$ to 1.06$)$ \\
\hline $30-41$ & 1 & 1 & 1 & 1 & 1 & 1 \\
\hline $42-59$ & 1.01 (0.98 to 1.04$)$ & 0.99 (0.96 to 1.02$)$ & 0.99 (0.96 to 1.02$)$ & $1.00(0.96$ to 1.03$)$ & $0.98(0.94$ to 1.02$)$ & 0.97 (0.94 to 1.01$)$ \\
\hline $60-89$ & $1.06^{* *}(1.02$ to 1.09$)$ & 1.03 (0.99 to 1.02 ) & $1.01(0.97$ to 1.00$)$ & $1.08^{* *}(1.03$ to 1.12$)$ & $1.05^{*}(1.00$ to 1.09$)$ & 1.01 (0.97 to 1.06$)$ \\
\hline $90+$ & $1.11^{* *}(1.06$ to 1.15$)$ & $1.06^{*}(1.01$ to 1.10$)$ & 0.96 (0.92 to 1.01$)$ & $1.11^{* *}(1.05$ to 1.16$)$ & 1.05 (1.00 to 1.11$)$ & 0.95 (0.90 to 1.00$)$ \\
\hline \multicolumn{7}{|c|}{ Interval 2nd-3rd birth (parents with $3+$ births) } \\
\hline 0 & $1.06(0.96$ to 1.17$)$ & 1.09 (0.98 to 1.21$)$ & $1.09(0.99$ to 1.21$)$ & $1.14^{*}(1.01$ to 1.29$)$ & $1.17^{* *}(1.04$ to 1.32$)$ & $1.18^{* *}(1.05$ to 1.33$)$ \\
\hline $0>18$ & $1.15^{* *}(1.09$ to 1.21$)$ & $1.13^{* *}(1.07$ to 1.19$)$ & $1.13^{* *}(1.07$ to 1.19$)$ & $1.06(0.99$ to 1.13$)$ & $1.05(0.98$ to 1.13$)$ & $1.06(0.99$ to 1.13$)$ \\
\hline $18-29$ & $1.10^{* *}(1.05$ to 1.15$)$ & $1.09 * *(1.04$ to 1.14$)$ & $1.09^{* *}(1.04$ to 1.14$)$ & 1.01 (0.96 to 1.07$)$ & 1.01 (0.96 to 1.07$)$ & 1.01 (0.96 to 1.07$)$ \\
\hline $30-41$ & 1 & 1 & 1 & 1 & 1 & 1 \\
\hline $42-59$ & $1.02(0.97$ to 1.07$)$ & $1.02(0.97$ to 1.06$)$ & $1.01(0.97$ to 1.06$)$ & $0.95 *(0.90$ to 1.00$)$ & $0.94^{*}(0.89$ to 1.00$)$ & $0.94^{*}(0.89$ to 0.99$)$ \\
\hline $60-89$ & $0.98(0.93$ to 1.02$)$ & $0.97(0.93$ to 1.02$)$ & $0.96 *(0.92$ to 1.01$)$ & $0.97(0.92$ to 1.03$)$ & $0.96(0.91$ to 1.00$)$ & $0.95^{*}(0.89$ to 1.00$)$ \\
\hline $90+$ & 0.99 (0.95 to 1.04$)$ & $0.97(0.92$ to 1.02$)$ & $0.91^{* *}(0.86$ to 0.98$)$ & $0.92^{* *}(0.86$ to 0.98$)$ & $0.89^{* *}(0.84$ to 0.95$)$ & $0.83^{* *}(0.77$ to 0.88$)$ \\
\hline \multicolumn{7}{|c|}{ Interval 3rd-4th birth (parents with 4 births) } \\
\hline 0 & 0.95 (0.81 to 1.10$)$ & 0.97 (0.83 to 1.13 ) & 0.97 (0.84 to 1.14$)$ & 0.98 (0.81 to 1.18$)$ & $1.00(0.83$ to 1.20$)$ & 1.00 (0.89 to 1.21$)$ \\
\hline $0>18$ & 1.10 (0.99 to 1.22$)$ & 1.09 (0.98 to 1.21$)$ & 1.09 (0.97 to 1.21$)$ & 1.07 (0.94 to 1.22$)$ & 1.06 (0.93 to 1.21$)$ & 1.07 (0.93 to 1.22$)$ \\
\hline $18-29$ & 1.08 (0.99 to 1.18$)$ & 1.08 (0.99 to 1.18$)$ & 1.08 (1.00 to 1.18$)$ & $1.14^{*}$ (1.02 to 1.26$)$ & $1.14^{*}$ (1.02 to 1.26$)$ & $1.14^{* *}(1.02$ to 1.27$)$ \\
\hline $30-41$ & 1 & 1 & 1 & 1 & 1 & 1 \\
\hline $42-59$ & $1.01(0.93$ to 1.10$)$ & $1.01(0.93$ to 1.10$)$ & 1.01 (0.92 to 1.10$)$ & 0.99 (0.89 to 1.11$)$ & 0.99 (0.89 to 1.10$)$ & 0.99 (0.88 to 1.07$)$ \\
\hline $60-89$ & 0.95 (0.87 to 1.04$)$ & 0.95 (0.87 to 1.04$)$ & 0.94 (0.86 to 1.03$)$ & 0.98 (0.88 to 1.09$)$ & 0.97 (0.87 to 1.08$)$ & 0.95 (0.86 to 1.07$)$ \\
\hline $90+$ & $0.93(0.85$ to 1.02$)$ & $0.91 *(0.83$ to 1.00$)$ & $0.87^{* *}(0.79$ to 0.96$)$ & $0.98(0.88$ to 1.10$)$ & 0.96 (0.86 to 1.08$)$ & 0.92 (0.82 to 1.04$)$ \\
\hline
\end{tabular}

Model 1: age; period; years of education; marital status. Model 2: + age at first birth; parity. Model 3: + change in coparent. Numbers of deaths and person years of exposure shown in table 2 and online supplementary table $\mathrm{S1}$.

${ }^{*} \mathrm{p}<0.05 ;{ }^{* *} \mathrm{p}<0.01$.

underlies long gaps between births that has implications for later parental health.

The rather similar effects that we observe for mothers and fathers-except in the case of twins-suggest that biosocial mechanisms may underlie linkages between birth interval lengths and mortality and health in midlife and later life. These may include the results of accumulated physical, emotional and economic stress arising from the demands of having closely spaced births and raising children close in age. Such effects might be greatest for socioeconomically disadvantaged groups, but in additional analysis (not shown) we found little evidence of interactions with educational status.

We used high-quality data from a complete population with little risk of bias from non-response or attrition as might be the case in survey-based studies or of bias arising from misreporting of fertility history, a known problem in retrospectively collected data. ${ }^{40}$ However, there are some limitations to this study. We only observed premature mortality and associations with mortality risks at older ages may be different. The data on prescription drug use were only available for a 5 -year period, interbirth interval lengths could only be approximated and inferences about morbidity based on drug use may be flawed.

There are also other factors which might confound associations between birth intervals and parents' health which we have been unable to take account of. Efficiency of contraceptive use and breastfeeding practices, for example, are important determinants of interpregnancy intervals and plausibly may be associated with other health-related behaviours. Any consequent confounding would not account for the association found between multiple births and later maternal mortality. However, the mechanisms underlying associations between experience of multiple births and experience of short intervals between singleton births with health may differ, as suggested by the fact that we found that the former was associated only with mothers' mortality, whereas closely spaced singleton births were also associated with fathers' mortality. Very short, and perhaps very long, interbirth intervals may be indicative of mistimed or unplanned fertility. This might also confound associations to some extent as there is evidence that mistimed or unintended births have negative implications for later maternal health. ${ }^{41}$ The birth of twins is also unplanned and parity-specific analysis showed that the positive association between having twins and mortality was restricted to mothers who did not progress to further births. These might include women for whom the birth of twins resulted in an eventual family size that was larger than intended and plausibly those who found raising twins particularly challenging.

The question we addressed in this paper represents a potentially important public health issue, especially as trends towards postponement of parenthood have led to an increase in parents who plan closely spaced families and, in some countries, parental leave regulations have had the effect of encouraging shorter birth intervals. ${ }^{5142}$ Additionally, the greater availability and use of assisted conception techniques has led to large increases in multiple births. ${ }^{43}$ Norway has an advanced economy and generous parental leave, childcare and other support services for families with children ${ }^{44}$ which, it has been suggested, may 
Table 4 Associations between length of interbirth interval and mortality in 1980-2008 by parity (ORs and 95\% Cls from discrete-time hazards models), men and women born during 1935-1968 and aged 40-73 years with two to four children

\begin{tabular}{|c|c|c|c|c|c|c|}
\hline \multirow[b]{2}{*}{ Months } & \multicolumn{3}{|l|}{ Men } & \multicolumn{3}{|l|}{ Women } \\
\hline & Parity 2 & Parity 3 & Parity 4 & Parity 2 & Parity 3 & Parity 4 \\
\hline \multicolumn{7}{|c|}{ Interval 1st-2nd birth } \\
\hline 0 & $1.07(0.92$ to 1.25$)$ & 1.14 (0.97 to 1.34$)$ & $0.78(0.59$ to 1.04$)$ & $1.36^{* *}(1.15$ to 1.61$)$ & $1.00(0.81$ to 1.24$)$ & $0.90(0.64$ to 1.27$)$ \\
\hline $0>18$ & $1.19^{* *}(1.12$ to 1.25$)$ & $1.17^{* *}(1.11$ to 1.23$)$ & $1.11^{* *}(1.03$ to 1.20$)$ & $1.16^{* *}(1.08$ to 1.24$)$ & $1.12^{* *}(1.05$ to 1.19$)$ & $1.10^{*}(1.00$ to 1.21$)$ \\
\hline \multicolumn{7}{|c|}{ Interval 2nd-3rd birtht } \\
\hline 0 & & $1.07(0.95$ to 1.20$)$ & $1.18(0.97$ to 1.44$)$ & & $1.26^{* *}(1.10$ to 1.44$)$ & $0.97(0.74$ to 1.26$)$ \\
\hline $0>18$ & & $1.14^{* *}(1.06$ to 1.22$)$ & $1.12^{*}(1.02$ to 1.22$)$ & & $1.10^{*}(1.00$ to 1.20$)$ & $1.00(0.90$ to 1.11$)$ \\
\hline \multicolumn{7}{|c|}{ Number of intervals $<18$ months } \\
\hline 0 & 1 & 1 & 1 & 1 & 1 & 1 \\
\hline 1 & $1.17^{* *}(1.11$ to 1.22$)$ & $1.12^{* *}(1.08$ to 1.16$)$ & $1.09^{* *}(1.03$ to 1.15$)$ & $1.18^{* *}(1.12$ to 1.26$)$ & $1.21^{* *}(1.12$ to 1.30$)$ & $1.06(0.99$ to 1.14$)$ \\
\hline 2 & & $1.41^{* *}(1.26$ to 1.58$)$ & $1.18^{* *}(1.08$ to 1.30$)$ & & $1.25^{* *}(1.16$ to 1.35$)$ & $1.06(0.94$ to 1.19$)$ \\
\hline 3 & & & $1.18(0.88$ to 1.57$)$ & & & $1.17(0.79$ to 1.72$)$ \\
\hline \multicolumn{7}{|c|}{ Average interval length } \\
\hline $0-17$ & & $1.22 *(1.12$ to 1.32$)$ & $1.19^{*}(1.04$ to 1.36$)$ & & $1.12^{* *}(1.01$ to 1.24$)$ & $1.22^{* *}(1.02$ to 1.44$)$ \\
\hline $18-29$ & & $1.07^{*}(1.02$ to 1.12$)$ & $1.10^{* *}(1.02$ to 1.18$)$ & & $1.06^{*}(1.00$ to 1.13$)$ & $1.01(0.92$ to 1.10$)$ \\
\hline $30-41$ & & 1 & 1 & & 1 & 1 \\
\hline $42-59$ & & $0.94^{*}(0.90$ to 0.98$)$ & $0.94(0.88$ to 1.01$)$ & & $0.94 *(0.89$ to 1.00$)$ & $1.00(0.92$ to 1.08$)$ \\
\hline $60-89$ & & $0.94^{*}(0.89$ to 0.98$)$ & $0.89 *(0.82$ to 0.98$)$ & & $0.91^{* *}(0.86$ to 0.97$)$ & $0.87^{*}(0.78$ to 0.98$)$ \\
\hline $90+$ & & $0.76^{* *}(0.70$ to 0.82$)$ & $0.74^{* *}(0.64$ to 0.87$)$ & & $0.85^{* *}(0.76$ to 0.94$)$ & $0.44^{* *}(0.25$ to 0.77$)$ \\
\hline Deaths & 22112 & 15093 & 6082 & 14736 & 10015 & 3981 \\
\hline Person years & 5692.9 & 3676.7 & 1210.0 & 5872.1 & 3879.1 & 1308.8 \\
\hline
\end{tabular}

Models include age; period; years of education; marital status, age at first birth and change in coparent since preceding birth.

${ }^{*} \mathrm{p}<0.05 ;{ }^{* *} \mathrm{p}<0.01$.

Reference category is $30-41$ months.

explain why high parity in Norway does not have the same adverse effects on parental mortality risks observed in other countries. $^{45}$ In less advantaged populations, stresses attendant on having closely spaced births-and their consequences for later parental health-may be greater and need investigation.
Further research is also needed to identify the mechanisms which underlie the associations reported. This would require prospective data including information on health-related behaviours and measures of stress during the childbearing and childrearing stages of life.

Table 5 Associations between the length of the first birth interval (in years) and mortality in 2004-2008 (ORs 95\% Cls from discrete-time hazards models) and indicators of use of prescription medicine (coefficients and standard errors from OLS regression models) in 2004-2008, men and women born during 1935-1968 with two to four children

\begin{tabular}{|c|c|c|c|c|}
\hline Birth interval (years) & Per cent in categoryt & OR $(95 \% \mathrm{CI})$ of mortality & Number of different medicines purchased & Number of diseases \\
\hline \multicolumn{5}{|l|}{ Men } \\
\hline $0-1$ & 10.8 & $1.14^{* *}(1.08$ to 1.21$)$ & $0.300 * *(0.029)$ & $0.141 * *(0.011)$ \\
\hline 2 & 24.5 & $1.05^{* *}(1.00$ to 1.10$)$ & $0.073(0.023)$ & $0.045^{* *}(0.009)$ \\
\hline 3 & 24.7 & 1 & 0 & 0 \\
\hline 4 & 15.8 & $0.95(0.90$ to 1.01$)$ & $-0.011(0.026)$ & $0.017(0.010)$ \\
\hline $5-6$ & 13.6 & 1.00 (0.95 to 1.06$)$ & $-0.012(0.027)$ & $0.018(0.010)$ \\
\hline $7+$ & 10.5 & $1.01(0.95$ to 1.08$)$ & $-0.026(0.033)$ & $0.001(0.013)$ \\
\hline \multicolumn{5}{|l|}{ Women } \\
\hline $0-1$ & 11.1 & $1.07^{* *}(1.00$ to 1.14$)$ & $0.129 * *(0.034)$ & $0.092 * *(0.011)$ \\
\hline 2 & 24.6 & $1.03(0.97$ to 1.09$)$ & $-0.004(0.027)$ & $0.020 * *(0.009)$ \\
\hline 3 & 24.3 & 1 & 0 & 0 \\
\hline 4 & 15.8 & 0.95 (0.89 to 1.01$)$ & $0.032(0.030)$ & $0.013(0.010)$ \\
\hline $5-6$ & 13.8 & 1.02 (0.95 to 1.11$)$ & $0.050(0.032)$ & $0.027^{* *}(0.010)$ \\
\hline $7+$ & 10.4 & 0.97 (0.90 to 1.04$)$ & $-0.121 * *(0.037)$ & $-0.021(0.012)$ \\
\hline
\end{tabular}




\section{What is already known on this subject}

Short and very long interbirth intervals are associated with worse perinatal, infant and short-term maternal outcomes. Two previous studies of UK populations have suggested longer term adverse effects of short birth intervals on parental health.

\section{What this study adds}

- This study shows that Norwegian parents with short intervals between singleton births, and mothers of twins, have higher mortality and greater use of prescription drugs in late midlife than parents with interbirth intervals of 31-41 months. Parents with very long interbirth intervals also had worse outcomes-but a large proportion of these had experienced a change of coparent and when this was allowed for the direction of the association reversed.

- Delayed childbearing and greater use of assisted reproduction mean that short birth intervals and multiple births are becoming more common. This study suggests that these trends might have negative implications for later life health and further work is needed to investigate underlying mechanisms.

Contributors EG designed the study and drafted the manuscript. OK contributed to the design, undertook the statistical analysis and commented extensively on the drafts.

Funding European Research Council Advanced Grant awarded to Emily Grundy, Reference number 324055.

Competing interests None.

Ethics approval Statistics Norway Ethical Review Board.

Provenance and peer review Not commissioned; externally peer reviewed.

Open Access This is an Open Access article distributed in accordance with the Creative Commons Attribution Non Commercial (CC BY-NC 4.0) license, which permits others to distribute, remix, adapt, build upon this work non-commercially, and license their derivative works on different terms, provided the original work is properly cited and the use is non-commercial. See: http://creativecommons.org/ licenses/by-nc/4.0/

\section{REFERENCES}

1 Cleland J, Conde-Agudelo A, Peterson $\mathrm{H}$, et al. Contraception and health. Lancet 2012;380:149-56.

2 Augur N, Daniel M, Platt RW, et al. The joint influence of marital status, interpregnancy interval, and neighbourhood on small for gestational age birth: a retrospective cohort study. BMC Pregnancy Childbirth 2008:8:7.

3 de Weger FJ, Hukkelhoven CW, Serroyen J, et al. Advanced maternal age, short interpregnancy interval, and perinatal outcome. Am J Obstet Gynecol 2011;2045:421.

4 Hogue $\mathrm{CJ}$, Menon R, Dunlop AL, et al. Racial disparities in preterm birth rates and short inter-pregnancy interval: an overview. Acta Obstet Gynecol Scand 2011;90:1317-24.

5 Nabukera SK, Wingate MS, Salihu HM, et al. Pregnancy spacing among women delaying initiation of childbearing. Arch Gynecol Obstet 2009;279:677-84.

6 Zhu BP. Effect of interpregnancy interval on birth outcomes: findings from three recent US studies. Int I Gynaecol Obstet 2005;89:S25-33.

7 Wendt A, Gibbs CM, Peters S, et al. Impact of increasing inter-pregnancy interval on maternal and infant health. Paediatr Perinat Epidemiol 2012;26(Suppl 1):239-58.

8 Conde-Agudelo A, Rosas-Bermudez A, Kafury-Goeta AC. Birth spacing and risk of adverse perinatal outcomes: a meta-analysis. JAMA 2006;295:1809-23.

9 WHO. Report of a WHO technical consultation on birth spacing. Geneva, Switzerland: WHO, 2007.

10 Conde-Agudelo A, Rosas-Bermudez A, Kafury-Goeta AC. Effects of birth spacing on maternal health: a systematic review. Am J Obstet Gynecol 2007;196:297-308.

11 Razzaque A, Da Vanzo J, Rahman M, et al. Pregnancy spacing and maternal morbidity in Matlab, Bangladesh. Int I Gynaecol Obstet 2005;89(Suppl 1):\$41-9.
12 Conde-Agudelo A, Rosas-Bermudez A, Castaño F, et al. Effects of birth spacing on maternal, perinatal, infant, and child health: a systematic review of causal mechanisms. Stud Fam Plann 2012:43:93-114.

13 Dewey KG, Cohen RJ. Does birth spacing affect maternal or child nutritional status? A systematic literature review. Matern Child Nutr 2007:3:151-73.

14 King JC. The risk of maternal nutritional depletion and poor outcomes increases in early or closely spaced pregnancies. J Nutr 2003;133(5 Suppl 2):1732S-6S.

15 van Eijsden M, Smits LM, van der Wal MF, et al. Association between short interpregnancy intervals and term birth weight: the role of folate depletion. Am J Clin Nutr 2008:88:147-53.

16 Davis EM, Babineau DC, Wang X, et al. Short inter-pregnancy intervals, parity, excessive pregnancy weight gain and risk of maternal obesity. Matern Child Health $J$ 2014;18:554-62.

17 Choi Y, Bishal D, Minkovitz CS. Multiple births are a risk factor for postpartum maternal depressive symptoms. Pediatrics 2009;123:1147-54.

18 Ross LE, McQueen K, Vigod S, et al. Risk for postpartum depression associated with assisted reproductive technologies and multiple births: a systematic review. Hum Reprod Update 2011:17:96-106.

19 Savitz DA, Stein CR, Ye F, et al. The epidemiology of hospitalized portpartum depression in New York State, 1995-2004. Ann Epidemiol 2011;21:399-406.

20 Jena $A B$, Goldman DP, Joyce G. Association between the birth of twins and parental divorce. Obstet Gynecol 2011;117:892-7.

21 Schmidt L, Sobotka T, Bentzen JG., et al Demographic and medical consequences of the postponement of parenthood. Hum Reprod Update 2011;18:29-43.

22 Tobias DK, Chavarro JE, Williams MA, et al. History of infertility and risk of gestational diabetes mellitus: a prospective analysis of 40,773 pregnancies. Am J Epidemiol 2013:178:1219-25.

23 Williams K, Umberson D. Marital status, marital transitions, and health: a gendered life course perspective. J Health Soc Behav 2004;45:81-98.

24 Blomgren J, Martikainen P, Grundy E, et al. Marital history 1971-91 and mortality 1991-2004 in England \& Wales and Finland. J Epidemiol Community Health 2012;66:30-6.

25 Kuh D, Shlomo YB, Susser E, eds. A life course approach to chronic disease epidemiology. Oxford: Oxford University Press, 2004.

26 Grundy E, Tomassini C. Fertility history and health in later life: a record linkage study in England and Wales. Soc Sci Med 2005:61:217-28.

27 Read S, Grundy E, Wolf D. Fertility history, health and health trajectories in later life: a study of older women and men in the British Household Panel Survey. Popul Stud 2011:65:201-15.

28 Kravdal O, Rindfuss R. Changing relationships between education and fertility: a study of women and men born 1940-1965. Am Sociol Rev 2008:73:854-73.

29 Furu K, Wettermark B, Andersen M, et al. The Nordic countries as a cohort for pharmacoepidemiological research. Basic Clin Pharmacol Toxicol 2011;106:86-94.

30 Grundy E, Kravdal Ø. Reproductive history and mortality in late middle age among Norwegian men and women. Am J Epidemiol 2008:167:271-9.

31 Hank K. Childbearing history, later-life health, and mortality in Germany. Popul Stud 2010;64:275-91.

32 Allison PD. Event history analysis: regression for longitudinal event data. Newbury Park, CA: Sage Publications, 1984

33 Statistics Norway. 2013. Deaths 2012. http://www.ssb.no/en/befolkning/statistikker/ dode/aar/2013-04-11

34 von Korff M, Wagner EH, Saunders KA. Chronic disease score from automated pharmacy data. J Clin Epidemiol 1992;45:197-203.

35 Johnson ML, El-Serag HB, Tran TT, et al. Adapting the Rx-risk-V for mortality predication in outpatient populations. Med Care 2006;44:793-7.

36 Grundy E, Sloggett A. Health inequalities in the older population: the role of personal capital, social resources and socio economic circumstances. Soc Sci Med 2003;56:935-47.

37 Kravdal $\varnothing$. The poorer cancer survival among the non-married in Norway: is much explained by comorbidities? Soc Sci Med 2013;81:42-52.

38 Kuo RN, Dong YH, Liu JP, et al. Predicting healthcare utilization using a pharmacy-based metric with the WHO's anatomical therapeutic chemical algorithm. Med Care 2011:49:1031-9.

39 Tomassini C, Grundy E, Skytthe A, et al. Twins and their health cost: consequences of multiple births on parental health and mortality in Denmark and England and Wales. Twin Res Hum Genet 2006:9:444-9.

40 Murphy M. Where have all the children gone? Women's reports of more childlessness at older ages than when they were younger in a large-scale continuous household survey in Britain. Popul Stud 2009;63:115-33.

41 Barber JS, Axinn WG, Thornton A. Unwanted childbearing, health, and mother-child relationships. J Health Soc Behav 1999:40:321-257.

42 Lalive R, Muller JF. How does parental leave affect fertility and return to work? evidence from two natural experiments. Q J Econ 2009;124:1363-402.

43 Kulkarni AK, Jamieson DJ, Jones HW, et al. Fertility treatments and multiple births in the United States. N Engl J Med 2013;369:2218-25.

44 Curtis L, Phipps S. Social transfers and the health status of mothers in Norway and Canada. Soc Sci Med 2004:58:2499-507.

45 Grundy E. Women's fertility and mortality in late mid-life: a comparison of three contemporary populations. Am J Human Biol 2009:21:541-7. 